\title{
Examining Failure Behaviour of Commercially Pure Titanium During Tensile Deformation and Hole Expansion Test
}

\author{
J.S Kwame ${ }^{1}$, E. Yakushina², P. Blackwell ${ }^{1,2}$ \\ 1. Department of Design, Manufacturing and Engineering Management, University of Strathclyde, Glasgow, \\ United Kingdom \\ 2. Advanced Forming Research Centre (AFRC), University of Strathclyde, Inchinnan, Renfrew, United Kingdom \\ E-mail: james.kwame@strath.ac.uk
}

Received: 8 April 2020; Accepted: 24 April 2020; Available online: 10 May 2020

\begin{abstract}
Hole expansion ratio is a material parameter which defines the extent to which sheet metals are formed. Research has shown that, the stress state observed at the hole edge after hole expansion test is similar to those observed during conventional uniaxial tensile test. However, conventional tensile test methods are not efficient in evaluating material edge formability. This work utilised optical non-contact measuring techniques to examine failure behaviour during tensile test and hole expansion test of commercially pure titanium sheet, fabricated with either abrasive water jet cutting or electric discharge machining. The work found that, the deformation mode in conventional tensile testing are governed by localised necking and subsequently diffused necking prior to failure. Deformation mode observed in hole expansion test is characterised by localised necking with no visible occurrence of diffused necking prior to failure. The highest strains are concentrated at the hole edge during hole expansion test due to their sensitivity to the hole preparation method with accompanying multiple localised necking sites resulting in non-uniform deformation. Strains become concentrated in the bulk material microstructure rather than the machined edge during tensile testing resulting in single localised deformation site and a more homogenous deformation.
\end{abstract}

Keywords: Titanium alloys; Tensile deformation; Hole expansion test; Edge conditions; Failure mode; Uniaxial stress state.

\section{Introduction}

Titanium and its alloys have been utilized in various applications mainly due to their high corrosion resistance, high fatigue toughness and high temperature strength [1]. However, one of the downsides of this material is their poor machinability, which has been attributed mainly to their low thermal conductivity, high temperature strength and low elastic modulus [2]. Reduced value of elastic modulus makes titanium parts susceptible to vibration and deflection during machining process [3]. Machining induced physiochemical functions are associated with the machined surface integrity properties, which affects the functional performance of components and potentially affect their manufacturing process [4]. Normally, the attained sheet edge roughness after machining is a function of the material property (texture) [5] and in some cases the technique used to process the sheet material [6]. Machining induced edge defects also act as stress raisers thereby optimizing the fatigue and fracture life [7-9], residual stress and hardness [10] of components. Electric discharge machining (EDM) and Abrasive water jet (AWJ) cutting are non-traditional cutting techniques adopted by industry mainly due to their better surface finish and versatility compared to their conventional counterparts [11]. The quality of titanium sheet edges produced after EDM [12-14] and AWJ [15, 16] cutting are a function of the adopted cutting parameters. Severity of defects generated on edge surfaces during machining have many impacts on the in-service performance of titanium and its alloy. Considering the sensitivity of titanium to notches and surface inhomogeneity, there is the need to ascertain if the edge surface asperities produced during machining impacts on their forming behavior.

For cumbersome forming techniques like sheet stretching, the prediction of the onset of necking of sheet limit strain is difficult. The hole expansion test (HET) is used to account for the edge forming limit strain of sheet metals for a given machined edge. The performance of a given hole edge stretching process is largely dependent on the tool geometry [17], the edge condition [18] and the cutting method [19]. The hole expansion ratio (HER) represents the extent of edge formability of sheet metals. The higher the HER, the higher the forming performance of the material. The HER is expressed by equation (1); 


$$
H E R=\frac{d_{f}-d_{0}}{d_{0}} \times 100 \%
$$

where $d_{f}$ is final hole diameter and $d_{0}$ is initial hole diameter.

Generally, the forming limit diagram (FLD) is a plot of the major and minor strain evolution during sheet metal forming under different stress states [20]. The FLD provides information on the limit to which sheet metals are safely formed as well as predicting regions at which failure occurs. The stress state observed at the hole edge after HET is the same as that observed during traditional tensile test [21]. However, traditional tensile test techniques are not effective for evaluating the edge formability of materials. This has informed the decision of some researchers to co-relate HER to tensile properties of materials such as; tensile strength [22], average plastic anisotropy and total elongation [23]. However, the co-relations are not able to explain the disparities in deformation modes observed for both forming methods. There is therefore the need to examine the nature of the failure modes attained during tensile deformation and HET in order to provide clarity on the deformation behavior attained in both techniques.

This research examines the effect of EDM and AWJ on the formability of commercially pure titanium (CP-Ti) grade 2 in order to ascertain the nature of the deformation modes observed during tensile deformation and HET using optical non-contact techniques. This work also provides useful data on the limit fracture strain attained during HET of CP-Ti grade 2 after AWJ and EDM machining. The fracture limit strains obtained in this research could implemented during HER modeling of this material.

\section{Experimental procedure}

\subsection{The material}

The material studied in this work is CP-Ti grade 2 sheet with a thickness of $1.6 \mathrm{~mm}$. CP-Ti grade 2 exhibits excellent strength to weight ratio and has the tendency to retain its strength substantially during deformation. Notable among their use in the aerospace industry is their adoption in airframe skin applications [24].

\subsection{Material preparation and characterization}

AWJ and EDM machining methods are used to fabricate the tensile specimens and the circular discs for the HET. A 150kN Zwick/ Roell Z150 load cell tensile testing machine, equipped with a programme service for the manoeuvre of its transverse motion was utilized to conduct a room temperature tensile test on the test samples in accordance with ISO 6892-1:2016. A constant strain rate of 0.001/s was used for the test, which was controlled by testXpert II software for a steadily changing crosshead speed. Digital image correlation (DIC) was used to evaluate the strain displacement during the tensile deformation process. The strain distribution after the tensile deformation was analyzed using Davis 8.0 software supplied by LAVision. For the HET, a 100mm diameter hemispherical punch was used to deform a $20 \mathrm{~mm}$ diameter hole until an edge crack occurred. The punch was driven at a steady speed of $1 \mathrm{~mm} / \mathrm{s}$. Gom Aramis software was used for strain analysis and GOM Atos software for evaluating sheet thickness evolution after deformation.

Material characterization was done by grinding and polishing using a Buehler Automet 300 Pro grinderpolisher machine. Scanning electron microscopy (SEM) was conducted on a Quanta FEG 250 microscope. Results after SEM analysis of the material in as-received condition revealed fine equiaxed grain structure with average grain size of $5.7 \pm 0.5 \mu \mathrm{m}$, Figure $1 a$. The material exhibited a highly anisotropic behaviour when examined in three sheet-processing directions at room temperature, Figure $1 b$.
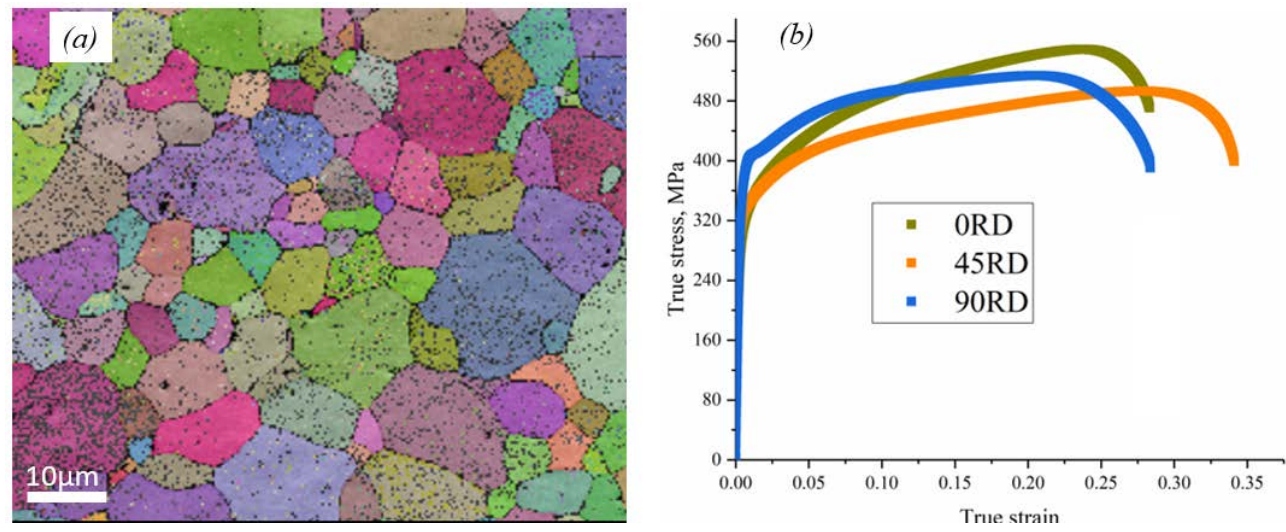

(a)SEM of as-received material, (b) Mechanical behaviour

Figure 1. Properties of as-received material 


\section{Results and discussion}

\subsection{Machined surface integrity}

The edge surface after AWJ cutting are characterized by its mechanical erosion attribute. The main edge surface defects observed are; micro-grooves, micro-indents, micro-scratches and micro-voids. These AWJ micro- defects were produced mainly by virtue of the paths travelled by the abrasive particles during the cutting process, Figure $2 a$. The EDM cut surface are characterized by; pockmarks, debris, micro-cracks and micro voids, due to its thermal erosion features, Figure $2 b$. EDM surface defects are mainly caused by re-melt solidification via dielectric fluid inability to wash away the molten material during the machining process.
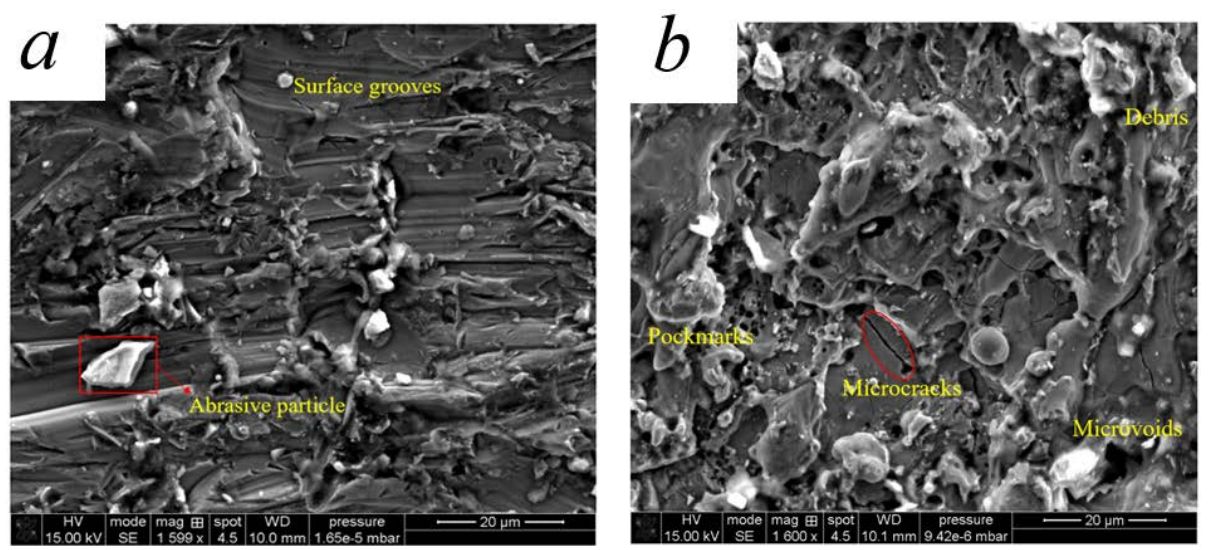

(a)AWJ surface, (b) EDM surface

Figure 2. SEM of machined surface of CP-Ti grade 2

\subsection{Strain path and stress state after HET}

The material after HET showed higher edge formability for EDM machined edge (195.9\%) compared to the edge prepared with AWJ (140.4\%), Figure 3a. The difference in edge forming performance could be attributed to the nature of the edge surface finishes attained after machining. Generally, better edge surface finish are obtained

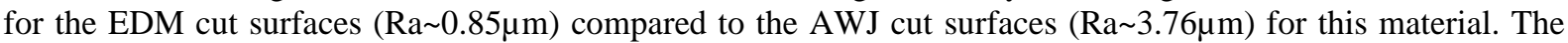
deeper micro-grooves seen in AWJ cut edges offered a fertile ground for crack nucleation and propagation resulting in early fracture. A plot of the major and minor strain path evolution at the hole edge after HET is shown in Figure $3 b$. The material showed lowered fracture limit strain for AWJ (0.5) compared to EDM (0.8) after HET. The major-minor strain path at the hole edge is consistent with the uniaxial stress state behaviour on the forming limit diagram [20].
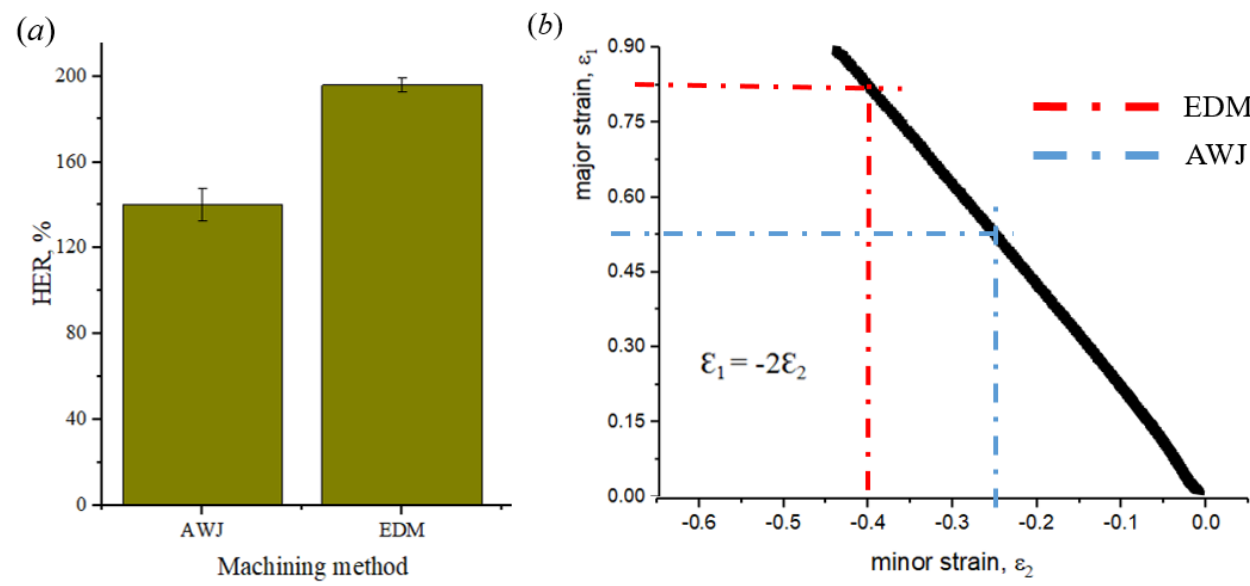

(a) HER after HET (b) Strain path at hole edge

Figure 3. Impact of machining method on edge formability

\subsection{Strain evolution during tensile test and HET}

Optical non-contact measurement techniques are used to ascertain the strain evolution during the deformation processes. Figure 4 shows DIC analysis of the global strain displacment in the plastic region during the tensile 
deformation process. The strain displacement appears to occur mostly within the bulk material microstructure rather than the machined edges. The strain distributions during tensile deformation are probably governed by the material texture. The strains displace and concentrate at high shear stress zones during localised necking with increasing deformation load, Figure $4 d$.
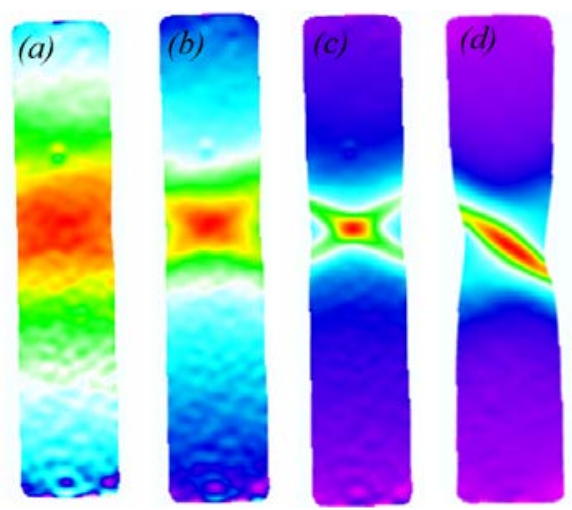

(a) $e=0.19$, (b) $e=0.26$, (c) $e=0.53$, (d) $e=1.15$

Figure 4. Strain displacement in the plastic region

Figure 5 shows the strain distribution of the samples after HET and uniaxial tensile test. For the tensile test sample, localised necking was observed followed by diffused necking with accompanying reduction in the gage width cross sectional area at the fracture zone prior to failure, Figure $5 a$. Shear stresses acting are optimum when acting at $45^{\circ}$ to the fracture line, and are concentrated in the localised necking region prior to failure. Gom Aramis analysis revealed that, the stresses acting are highest around the hole edge after HET, Figure $5 b$. Localised necking was observed at the crack edge with no visible reduction in the local width at the crack site, (Figure $5 b$ inset). The exerted shear stresses are highest, when acting $45^{0}$ to the applied load resulting in failure at edges where those stresses exist. This occurrence was the main reason for the visible $45^{\circ}$ angled fracture line after HET (red line in Figure $5 b$ inset), similar to the shear angle observed in tensile deformation. However, the main difference observed during the deformation processes lies in the necking morphology. Localised necking followed by diffused necking are observed in the tensile deformation process. Failure observed after HET however is characterised by localised necking with no visible diffused necking prior to fracture. Shear stresses are observed to act in both deformation processes, reminiscent of ductile shear fracture deformation mechanism.

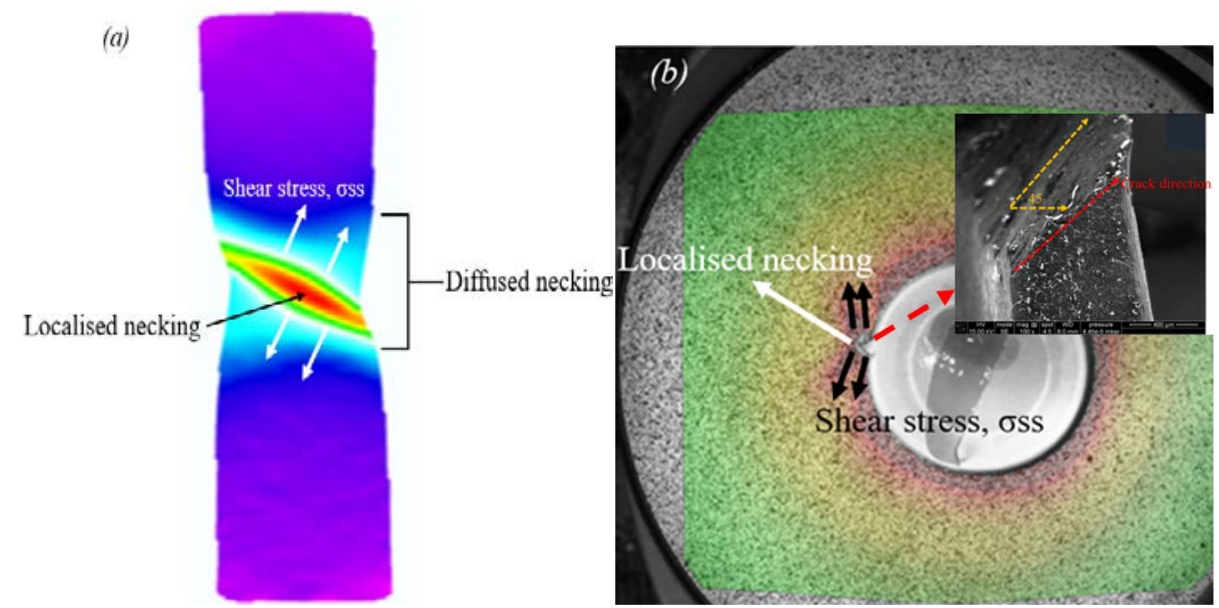

(a)Tensile strain evolution, (b) Strain evolution during HET (inset:SEM of hole edge)

Figure 5. Deformation mode analysis

Another striking difference observed between the conventional tensile deformation behaviour and HET is the number of localised necking sites observed. There exist the tendency for the occurrence of numerous localised necking sites during HET (Figure 6), compared to the single localised necking site observed during conventional tensile test. These multiple localised necking sites serve as zones of high strain gradient, making the prediction of the HER based solely on tensile deformation parameters (where generally only one form of localised necking occurs) very cumbersome.

Figure 7 shows Gom Atos analysis after fracture of the samples after HET and tensile test. Uniform sheet 
thinning are observed for the tensile test samples at localised necking zones, Figure $7 b$. The changes in morphology of the localised necking with sheet-processing direction confirms the responsiveness of the strain displacement to the material texture, Figure $7 b$. The sample after HET also showed thinning at the localised necking regions. The higher number of localised necking seen after HET resulted in non-uniform thinning leading to higher deformation gradients at the hole edge region, Figure $7 a$.

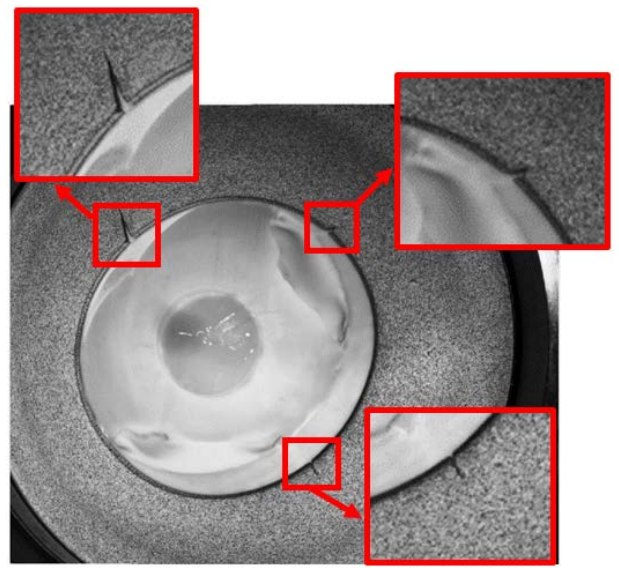

Figure 6. Multiple localised necking sites during HET
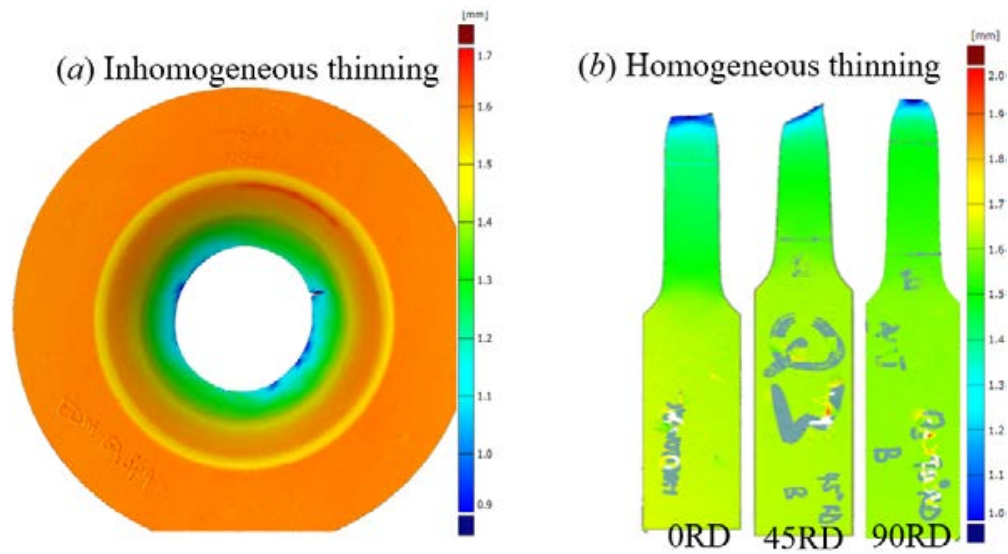

(a)HET at fracture, $(b)$ Tensile test at fracture

Figure 7. Nature of thinning distribution at failure

\section{Conclusion}

Uniaxial stress state is observed at the hole edge after HET which is synonymous with the stress state observed during traditional tensile testing. However, conventional tensile testing methods are not suitable for determining the HER of sheet materials. This work used optical non-contact techniques to examine the failure processes after tensile test and HET in order to understand the nature of their deformation behaviour at failure. The work found that;

1) Tensile deformation at fracture is generally characterised by localised necking followed by diffused necking. However, only localised necking is observed after HET. Shear stresses are observed to act for both forming techniques and are aligned $45^{\circ}$ to the crack axes at optimum values, reminiscent of ductile shear fracture mechanism

2) The occurrence of high number of localised necking sites after HET results in non-uniform thinning around the hole edge, leading to the formation of high deformation gradients. Single localised necking site occurs after tensile testing resulting in a more homogeneous deformation

3) Apart from material microstructure, the type of machining method adopted have major impact on the edge formability of CP-Ti grade 2. The material exhibited higher edge forming performance (195.5\%) with higher fracture strain limit (0.8) for EDM cut edges compared to AWJ cut edges (HER:140.\%, fracture strain limit: 0.5). Strain evolution during HET are highest at the hole edge at fracture.

4) Strain displacement during traditional tensile testing is governed mainly by the material texture and occurs away from the sheet edge, thereby proving independent of the sheet machining method 


\section{References}

[1] Pervaiz S, Rashid A, Deiab I, Nicolescu M. Influence of tool materials on machinability of titanium and nickel based alloys: a review. Materials and Manufacturing Processes. 2014; 29(3):219-252.

[2] Colafemina JP, Jasinevicius RG, Duduch JG. Surface integrity of ultra-precision diamond turned Ti (commercially pure) and Ti alloy (Ti-6Al-4V). Proc.IMechE Part B: Journal of Engineering Manufacture. 2007; 221:999-1006.

[3] Veiga C, Davim J P, Loureiro AJ. Review on machinability of titanium alloys: the process perspective. Reviews on Advanced Materials Science. 2013; 34:148-164.

[4] Gómez-Parra A, Puerta FJ, Rosales EI, González-Madrigal JM, Marcos M. Study of the influence of cutting parameters on the Ultimate Tensile Strength (UTS) of UNS A92024 alloy dry turned bars. Procedia Engineering. 2013;63:796-803.

[5] Banovic S, Foecke T. Evolution of strain-induced microstructure and texture in commercial aluminium sheet under balanced biaxial stretching. Metallurgical and Materials Transaction A. 2003; 34A: 657-671.

[6] Zelenak M, Valicek J, Klich J, Zidkova P. Comparison of surface roughness quality created by abrasive water jet and CO2 laser beam cutting. Technicki Vjesnik. 2012;19(3): 481-485.

[7] Yuri T, Ono Y, Ogata T. Effects of surface roughness and notch on fatigue properties for Ti-5Al-2.5Sn ELI alloy at cryogenic temperatures. Science and Technology of Advanced Materials. 2003;4(4): 291-299.

[8] Novovic D, Dewes RC, Aspinwall DK, Voice W, Bowen P. The effect of machined topography and integrity on fatigue life. International Journal of Machine Tools \& Manufacturing. 2004;44:125-134.

[9] Javidi A, Rieger U, Eichlseder W. The effect of machining on the surface integrity and fatigue life. International Journal of Fatigue. 2008; 30: 2050-2055.

[10] Jawahir IS, Brinksmeier E, M'Saoubi R, Aspinwall DK, Outeiro JC, Meyer D, Umbrello G, Jayal AD. Surface integrity in material removal processes: Recent advances. CIRP Annals- Manufacturing Technology. 2011; 60: 603-623.

[11] Akkurt A. The effect of cutting process on surface microstructure and hardness of pure and Al 6061 aluminium alloy. Engineering Science and Technology, An International Journal. 2015; 18(3): 303-308.

[12] Hascalik A, Caydas UA comparative study of surface integrity of Ti-6Al-4V alloy machined by EDM and AECG. Journal of Materials Processing Technology. 2007; 190: 173-180.

[13] Kumar A, Kumar V, Kumar J. Investigation of machining parameters and surface integrity in wire electric discharge machining of pure titanium. Journal of Engineering Manufacture. 2013; 227(7): 972-992.

[14] Yan BH, Tsai HC, Huang FY. The effect of EDM of a dielectric of a urea solution in water on modifying the surface of titanium. International Journal of Machine Tools and Manufacture. 2005; 45: 194-200.

[15] Hascalik A, Caydas U, Gurun H. Effect of tranverse speed on abrasive waterjet machining of Ti-6Al-4V alloy. Materials and Design. 2007; 28(6):1953-1957.

[16] Chao J, Zhou G, Leu MC, Geskin E. Characteristics of abrasive water jet generated surfaces and effects of cutting parameters and structure vibration. Transactions of ASME. 1995; 117: 516-525.

[17] Pathak N, Butcher C, Worswick M. Assessment of the critical parameters influencing the the edge stretchability of advanced high-strength steel sheet. Journal of Materials Engineering and Performance. 2016; 25(11): 4919-4932.

[18] Gläsner T, Schneider M, Troitzsch M, Westhäuser S. Considering the edge-crack sensitivity of a hot-rolled steel in forming simulation. IOP Conference Series: Materials Science and Engineering. 2016;159(1):1-17.

[19] Nagasaka A, Kubota Y, Sugimoto KI, Mio A, Hojo T, Makii K, Kawajiri M, Kitayama M. Effect of YAG laser cutting on stretch-flangeability of ultra high strength TRIP sheet steel with bainitic ferrite matrix. ISIJ International. 2010;50(10):1441-1446.

[20] Asadi M, Schulze N, Palkowski H. Use of the aging effect to change the local properties of structure components. Advanced Materials Research. 2010; 137: 35-79.

[21] Paul SK, Mukherjee M, Kundu S, Chandra S. Prediction of hole expansion ratio for automotive grade steels. Computational Materials Science. 2014; 89: 189-197.

[22] Chen X, Jiang H, Cui Z, Lian C, Lu C. Hole expansion characteristics of ultra high strength steels. Procedia Engineering. 2014;81:718-723.

[23] Adamczyk RD, Michal GM. Sheared edge extension of high-strength cold-rolled steels. Journal of Applied Metal Working. 1986; 4(2): 157-163.

[24] Peters M, Kumpfert J, Ward CH, Leyens, C. Titanium alloys for aerospace application. Advanced Engineering Materials. 2003;5(6): 419-427.

(C) 2020 by the author(s). This work is licensed under a Creative Commons Attribution 4.0 International License (http://creativecommons.org/licenses/by/4.0/). Authors retain copyright of their work, with first publication rights granted to Tech Reviews Ltd. 